\title{
UM MODELO DE SUPERVISÃO CLÍNICA NA FORMAÇÃO DO ESTUDANTE DE PSICOLOGIA: A EXPERIÊNCIA DA UFC
}

\author{
Mônica Teles Tavora*
}

\begin{abstract}
RESUMO. Este trabalho apresenta um modelo de supervisão que tem por objetivo promover o crescimento pessoal e técnico de terapeutas iniciantes. Embora os princípios gerais da Abordagem Centrada na Pessoa e da Socionomia (referencial psicodramático) sejam os pilares da metodologia de supervisão desenvolvida no estágio clínico do Curso de Psicologia da Universidade Federal do Ceará, a proposta é ampla o suficiente para ser aplicada em treinamentos de orientações humanistas em geral. A utilização da Socionomia no trabalho em grupo pressupõe uma aprendizagem compartilhada na qual cada participante é promotor de seu próprio crescimento e dos demais.
\end{abstract}

Palavras-chaves: supervisão, trabalho em grupo, suporte afetivo e técnico.

\section{A MODEL OF CLINICAL SUPERVISION IN THE FORMATION OF PSYCHOLOGY STUDENTS: THE UFC EXPERIENCE}

\begin{abstract}
This work presents a supervision model with the objective of promoting the personal and technical growth of new therapists. Although the general principles of the Person-Centered Approach and Socionomy (psychodrama referential) are pillars of the supervision methodology developed in a clinical training of the Psychology curriculum at the Federal University of Ceará, the proposal is flexible enough to be applied to humanist orientation training in general. The use of Socionomy in group sessions presupposes shared learning where each participant is the promoter of his own as well as the growth of others.
\end{abstract}

Key words: supervision, group sessions, affective and technical support.

Treinar futuros terapeutas exige, ao mesmo tempo, técnica, arte e sensibilidade. Exige respeito às diferenças e crença no talento que pode brotar de cada iniciante amedrontado, tímido em suas iniciativas e pouco confiante em si. Significa também deixar que os treinandos ensinem ao supervisor a arte de ser paciente, de acreditar sem ver resultados imediatos e de abster-se de induzi-los a um modelo de terapeuta já pronto.

Supervisionar um processo de atendimento psicoterápico tem como objetivo transmitir ensinamentos básicos mas, principalmente, fazer com que cada estagiário olhe para dentro de si, para a relação que estabelece com seu cliente e para o vínculo que desenvolve com seu supervisor. Treinar em grupo é inserir o terapeuta iniciante em um mundo de relações reais e presentes onde ele pode avaliar-se, espelhar-se e se encontrar com o outro. É prepará-lo para a relação profunda que se estabelece entre terapeuta e cliente.

O modelo de intervenção apresentado vem sendo utilizado no estágio clínico anual do Curso de Psicologia da Universidade Federal do Ceará. Está voltado, particularmente, para o treinamento de profissionais iniciantes que desejam atuar como terapeutas individuais, de grupo ou de casais. Embora os princípios gerais da abordagem centrada na pessoa e os recursos psicodramáticos sejam os pilares de suporte da metodologia de supervisão desenvolvida, a proposta é ampla o suficiente para ser aplicada em treinamentos de orientações humanistas em geral.

As intervenções propostas foram sendo organizadas ao longo da vivência cumulativa de vários anos de supervisão. A prática clínica da autora em

Psicóloga, mestre em Estudos de Família pela Purdue University, Indiana, EUA, professora adjunta e supervisora de estágio clínico no Departamento de Psicologia da Universidade Federal do Ceará, psicodramatista pela FEPS do Brasil, psicoterapeuta de casal e família.

Endereço para correspondência: Rua Leonardo Mota, 2815 - 103, 60170-041, Fortaleza-CE. E-mail: monicatavora@bol.com.br 
atendimento centrado na pessoa foi posteriormente complementada por um curso de formação em psicodrama que veio atender à necessidade de maior utilização de recursos técnicos, principalmente no trabalho com casais. A articulação destas duas orientações teóricas foi fruto de um movimento criativo e de identificação pessoal com o principio comum às atitudes facilitadoras rogerianas e à abordagem socionômica de Moreno, ambas possibilitando e estimulando a inovação e a confirmação da diferença.

\section{A ABORDAGEM CENTRADA NA PESSOA}

Carl Rogers, psicólogo americano criador de 'terapia centrada no cliente', desenvolveu uma abordagem terapêutica em torno da premissa de que existe em cada cliente, como em qualquer ser humano, um movimento natural para o crescimento e para a expansão de si, a que ele chamou de tendência atualizante (ou tendência à realização). Para que esta tendência possa efetivar-se, terapeuta e cliente precisam estabelecer uma relação significativa que favoreça o encontro. Nestas condições interpessoais favoráveis, o terapeuta torna-se a pessoa facilitadora deste processo de descoberta e criação em que se lança o cliente:

Existe em todo organismo, em qualquer nível, em fluxo subjacente de movimento para uma realização construtora de suas potencialidades intrínsecas. Há no homem uma tendência natural para o desenvolvimento completo. O termo mais freqüentemente usado para isso é o de tendência de realização, que está presente em todos os organismos vivos. (Rogers, 1978, p. 17).

Três atitudes essenciais devem estar presentes na relação terapêutica: consideração positiva incondicional, compreensão empática e autenticidade.

- Compreensão empática: atitude que possibilita ao terapeuta ser tocado pela pessoa do cliente e apreender a sua vivência particular a partir de uma significação pessoal. Neste processo, o terapeuta, sendo ele mesmo, com sua vivência também particular, toca o cliente e expressa a si mesmo autenticamente.

- Consideração positiva incondicional: receber consideração positiva representa, segundo a abordagem centrada na pessoa, uma necessidade universal do ser humano. Ao ser considerado incondicionalmente por uma pessoa significativa, em uma vivência grupal ou bipessoal, o indivíduo arrisca-se a, gradualmente, reconhecer sentimentos anteriormente temidos e negados. Isto possibilita a elaboração de suas vivências, resultando na busca de comportamentos criativamente mais adaptativos e em acordo com seu próprio movimento interior. A possibilidade de oferecer consideração positiva está diretamente ligada à condição pessoal do terapeuta de vivenciar plenamente a relação terapêutica. Desta forma, ambos os parceiros se influenciam mutuamente, dando às atitudes facilitadoras uma dimensão dinâmica de duplo sentido.

- Autenticidade: ao ser autêntico, o terapeuta se apresenta ao cliente com um acordo interno, isto é, em pleno contato com suas próprias experiências. Quando se comunica com o cliente, está sendo ele mesmo, sem máscaras e sem aspectos negados ou escondidos de si mesmo.

Inicialmente formuladas por Rogers como atitudes que provinham exclusivamente do terapeuta, as condições facilitadoras são hoje compreendidas por seus seguidores como uma vivência intersubjetiva da qual participam o terapeuta e o cliente. Originando-se da experiência clínica com o nome de 'terapia nãodiretiva', o método de Rogers passou posteriormente a se chamar 'abordagem centrada na pessoa', não só pelo reconhecimento gradual da natureza bidirecional das relações de crescimento, como também pela expansão da proposta rogeriana para vários campos das relações humanas.

\section{AS ATITUDES FACILITADORAS NO GRUPO}

Assim como considera o indivíduo digno de confiança para se autogerir, movido por uma tendência natural para a realização, Rogers também reverencia a 'sabedoria do grupo', confiando no seu potencial auto-regulador e transformador na presença de condições favoráveis. Tais condições referem-se ao contato com uma pessoa facilitadora que possa reconhecer e confirmar este movimento natural.

Em seu livro Grupos de Encontro, este autor descreve exaustivamente seu trabalho em contextos grupais. Ao escrever Um Jeito de Ser, trata principalmente do trabalho com grandes grupos em experiências de workshops por vários países. Trabalhando com um só indivíduo, com pequenos grupos ou em grandes comunidades, Rogers reafirma sua profunda crença no potencial auto-regulador do 'organismo'. 
As condições terapêuticas facilitadoras traduzemse na vivência grupal através de um movimento direcionado para o crescimento e propagador da ação terapêutica entre os membros do grupo:

Mas, na presença de uma atitude facilitadora
criada pela equipe e por muitos participantes,
os indivíduos gradualmente começam a ouvir
uns aos outros e, lentamente, a compreender
e a respeitar. O ambiente torna-se propício ao
trabalho, tanto nos grandes quanto nos
pequenos grupos, à medida que as pessoas
começam a pesquisar a si mesmas e a seus
relacionamentos. (Rogers, 1983, p. 60 )

A contribuição teórica e técnica da abordagem centrada na pessoa para a aprendizagem dos estagiários em supervisão pode ser observada nas vivências descritas e nas intervenções do exemplo ilustrativo apresentado mais adiante neste trabalho. Essa orientação teórica oferece o princípio norteador da conduta do supervisor, privilegiando a confirmação da existência das pessoas participantes do processo grupal e crendo no potencial auto-atualizador dos estagiários individualmente e do grupo como um todo. Estes fatores, embora nem sempre tão evidentes à primeira vista, formam o alicerce que dá suporte à atuação do supervisor na referida experiência.

Somente ao se sentirem acolhidos e confirmados, os terapeutas iniciantes podem se abrir para os desafios da experiência clínica, utilizando seus próprios erros e conquistas na construção de uma identidade profissional integrada com seu crescimento pessoal. Esta vivência sedimenta os vínculos dentro do grupo, estimula a reflexão dos participantes e permite vislumbrar soluções para as dificuldades encontradas em seus atendimentos.

\section{O PSICODRAMA}

Jacob Levy Moreno, médico romeno judeu, criou a sociometria, o psicodrama e a psicoterapia de grupo, posteriormente organizando sua obra no que chamou de 'ciência socionômica'. Seu interesse central era estudar o homem-em-relação: tinha preferência por trabalhar em grupo, mantendo um olhar atento tanto no processo grupal como na dinâmica individual de cada um de seus participantes. Considerava ele que o 'eu', isto é, a noção de identidade pessoal, se forma a partir das experiências sociais que se iniciam desde as primeiras interações do bebê com sua mãe. A criação do conceito de 'papel' veio possibilitar a exteriorização da 'personalidade' em um contexto interacional e desestimular, no meio psicodramático, estudos baseados em inferências sobre os atributos intrapsíquicos de indivíduos. Denominou Moreno de 'papéis psicodramáticos' à manifestação particular, individualizada, de um determinado papel social. Este conceito, fortemente influenciado pela experiência em teatro de seu criador, não só expressa a posição que uma determinada pessoa ocupa em relação aos outros componentes de um grupo social, como também permite avaliar os atributos pessoais dos indivíduos em interação.

Costa (1996) desenvolveu um trabalho meticuloso de sistematização da teoria moreniana, dando organização à obra e possibilitando uma compreensão da prática psicodramática mais abrangente e inserida no contexto filosófico e teórico da ciência socionômica. Esta autora compreende a socionomia como a ciência que estuda as leis que regem os sistemas sociais com suas forças naturais autoorganizadoras e auto-integrativas, que podem ser utilizadas para promover mudança e crescimento. Desta forma, um trabalho de relações norteado pela proposta moreniana deve desenvolver-se no grupo sem perder de vista sua inserção no sistema social mais amplo e sua capacidade transformadora da sociedade.

A utilização da socionomia no trabalho em grupo com objetivo de aprendizagem e supervisão foi desenvolvida por Costa (2000). O processo de aprendizagem deve privilegiar, segundo esta autora, o homem espontâneo e criativo em seu contexto interacional. O aprendiz é colaborador de um processo de criação conjunta que promove a adequação pessoal e social. A supervisão em grupo é, pois, mais do que um intercâmbio de experiências que objetiva trabalhar as vivências de cada treinando com seus clientes; visa também à formação de vínculos dentro do próprio grupo, entre os novos terapeutas, que, longe de serem meras telas de projeção das relações particulares de cada participante, são produtores de vínculos vivos e atuais, liberadores da espontaneidade e validadores do crescimento mútuo.

Neste processo, cada participante é promotor de seu próprio crescimento e dos demais. A proposta de transformação socionômica objetiva uma aprendizagem que se dá através da liberação de espontaneidade e do reconhecimento, por cada indivíduo, de seu potencial transformador de si e do grupo. Neste sentido, cada novo terapeuta é um agente de transformação social como ser criativo e criador, colaborador de um processo de crescimento coletivo onde tem como parceiro e co-participante o seu supervisor. 


\section{A matriz de identidade}

O conceito de matriz de identidade desenvolvido por Moreno (1997) refere-se ao conjunto de condições psicológicas e sociais no qual a criança é inserida ao nascer. Ao longo de seu desenvolvimento emocional e construção de sua identidade, ela passa por cinco fases:

\section{Indiferenciação}

É o momento evolutivo em que a criança ainda não se distingue das pessoas com quem interage: ela e o mundo são uma única coisa, uma massa informe sem contornos definidos. Pessoas e objetos se confundem; as fronteiras entre o interno e o externo estão diluídas.

\section{Reconhecimento do Eu}

Nesta fase, a criança está com sua atenção centrada em si: nos contornos do seu corpo, no reconhecimento de si no espelho. Ao perceber que seu corpo está separado da mãe, das pessoas, dos objetos, concentra sua energia em explorar o reconhecimento de suas fronteiras.

Este processo é o resultado de um contínuo jogo de papéis entre o bebê e seu ego-auxiliar, a mãe. A partir das experiências psicossomáticas da alimentação e dos cuidados maternos, a criança vai identificando suas necessidades e o movimento do outro para satisfazê-las. É, portanto, sempre no contexto interpessoal que a aprendizagem emocional e a definição da identidade se processam.

\section{Reconhecimento do Tu}

Caracteriza-se pela exploração do diferente, do que não é o eu. Através deste processo de reconhecimento do que não é próprio, a criança fortalece a sua identidade. $\mathrm{O}$ tu, nesse momento, é meramente instrumental, ou seja, está convenientemente a serviço do processo de reconhecimento do eu. É a fase da exploração do mundo, do diferente, da descoberta de que o outro age e reage diferentemente dela, criança..

\section{Pré-inversão}

É a fase em que a criança começa a se experimentar no papel do outro. Ainda é uma vivência automatizada, carecendo de sensibilidade para a experiência alheia. É a fase da imitação, do faz-de-conta, uma espécie de ensaio e preparação para uma futura inversão, quando a reciprocidade estará então presente.

\section{Inversão de papéis}

Experiência indicadora do amadurecimento emocional, em que o indivíduo não só se percebe separado do outro como também é capaz de compreender a significação de sua vivência diferenciada. A capacidade de se colocar no lugar do outro e a possibilidade de que este se coloque em seu lugar criam as condições necessárias para que se realize um verdadeiro encontro, uma experiência produtora de crescimento para ambos os participantes e fortalecedora do vínculo.

Apesar de se iniciar com o nascimento e se desenrolar em grande parte nos primeiros anos de vida de um indivíduo, este movimento evolutivo não é retilíneo e pode sofrer avanços e retrocessos ao longo das várias vivências que pontuam a sua existência. $\mathrm{Na}$ adolescência, por exemplo, as mudanças físicas, emocionais e sociais provocam uma reativação de vivências características da fase do reconhecimento do eu. O momento de definição profissional para o adulto jovem pode configurar-se como outro ponto crítico na construção e revisão de sua identidade.

O estágio curricular que deve ser cumprido pelo estudante de psicologia prepara a sua entrada no mundo profissional, experiência caracteristicamente pontilhada de ansiedades e incertezas quanto à sua condição para um desempenho satisfatório e bemsucedido. Um fator agravante desta vivência é a natureza peculiar do instrumento de trabalho do psicólogo que se define como a própria relação terapêutica, à qual deve estar subordinado o aparato técnico utilizado. Nestas condições, o estagiário de psicologia clínica necessita não só do suporte de sua própria psicoterapia, como também do apoio de um trabalho pessoal e relacional no contexto da supervisão.

\section{A ESTRUTURA DO ESTÁGIO}

O Curso de Psicologia da Universidade Federal do Ceará tem, tradicionalmente, formado profissionais nas áreas clínica, escolar e organizacional. Entretanto, nos últimos anos, vem crescendo o interesse de estagiários e supervisores para atuar também nas áreas comunitária e hospitalar. A prática nos últimos semestres do curso realiza-se através de um estágio obrigatório de quinhentas horas em uma das áreas mencionadas. $\mathrm{O}$ estágio opcional, com carga horária de duzentas horas, deve acontecer como uma experiência adicional em outra área.

O modelo de supervisão aqui descrito é utilizado com alunos que se matriculam no estágio anual de psicologia clínica. $\mathrm{O}$ treinamento regular de um ano compreende quarenta sessões de supervisão em grupo, com duração de três horas, quando são realizadas apresentações e/ou dramatizações dos casos em 
atendimento, discussões teóricas e vivências. Outras atividades como leituras, planejamento e avaliação de sessões grupais, encaminhamento de clientes ou atendimentos de emergência devem complementar a experiência de supervisão.

O treinando deverá cumprir duzentas horas de atendimento individual ou grupal. Como parte desta carga horária, ele poderá, após o primeiro semestre de atendimento, fazer triagens de clientes que serão encaminhados para outros estagiários. Este encaminhamento é feito por ocasião da supervisão dos estagiários que recebem o caso e é, por este motivo, creditado como duas horas de atividade clínica para o estagiário triador.

Cada estudante deve atender, em média, a seis clientes ou o correspondente em horas de atendimento em grupo, para que tenha, ao final do período regular, cumprido a carga horária necessária para a sua aprovação no estágio. Caso isto não aconteça, ele poderá assinar um termo de compromisso para complementação das horas restantes após a conclusão do período oficial.

A população atendida na clínica-escola consiste de pessoas da comunidade com baixo poder aquisitivo, incluindo as classes baixa e média-baixa, com um número significativo de estudantes universitários. O pagamento é feito por meio de uma taxa significativamente reduzida, variando de acordo com a faixa salarial do candidato a atendimento.

A questão burocrática, relativa ao cumprimento de horas, pode levar o estagiário a utilizar o cliente como instrumento de suas conveniências acadêmicas. $\mathrm{Na}$ medida em que lida com questões como o momento da alta, abandono da terapia, faltas, férias etc, ele entra em contato com sua condição para respeitar as necessidades do cliente e, ao mesmo tempo, levar em conta seus próprios limites. O supervisor tem um papel fundamental no acompanhamento do estagiário no momento em que, por exemplo. este se depara com o encerramento de um processo terapêutico antes da conclusão do estágio ou quando necessita receber um novo cliente para cumprir o tempo necessário de atividade clínica em um momento próximo à conclusão do curso.

Estas questões, que aparentemente representam inconveniência necessária na formação do estudante de psicologia, podem converter-se em valiosa preparação para futuras situações profissionais. Se o novo profissional não mais precisa cumprir carga horária, deve, por outro lado, considerar o fator remuneração. Isto é, lidar com 'créditos' de natureza diferente, mas que perpassam pelas mesmas questões práticas e se entrelaçam na relação e vivência com seu cliente.

\section{A PREPARAÇÃO PARA O ESTÁGIO}

Ao longo do Curso de Psicologia, o estudante tem contato com várias abordagens teóricas e estilos pessoais dos professores-supervisores. O estudo da teoria leva também o aluno a questionar-se sobre sua condição para atuar como profissional de psicologia. Alguns iniciam um processo pessoal de psicoterapia como resultado destas reflexões, envolvem-se em grupos de estudo ou procuram cursos complementares paralelamente à formação acadêmica; outros deparamse com a urgência de eleger um referencial teórico e investir em seu aprimoramento pessoal somente quando o início do estágio se aproxima.

O estagiário geralmente faz a escolha de seu supervisor de acordo com alguns critérios: área de atuação preferida, abordagem teórica de maior identificação, simpatia e/ou afinidade com o supervisor e disponibilidade deste. Com a rotatividade de supervisores provocada pela saída de professores para cursos de pós-graduação ou desligamento por aposentadoria, a disponibilidade do supervisor tornase algumas vezes o critério de escolha mais forte. $\mathrm{Na}$ experiência de supervisão apresentada aqui, no entanto, raros são os casos em que o estagiário inicialmente indefinido quanto à sua identificação com o supervisor não termine por se envolver no processo interativo do grupo de supervisão. Neste contexto, são trabalhados não só a relação de cada novo terapeuta com seu cliente mas também os vínculos estagiárioestagiário e estagiário-supervisor, o que facilita a elaboração das escolhas feitas pelo estudante durante todo o seu processo de treinamento.

Ao iniciar o treinamento como terapeuta, os estudantes estão em diferentes estágios de amadurecimento pessoal e profissional. No entanto, todos se deparam com as mesmas angústias provocadas pelos primeiros contatos com os clientes. No processo de internalização de um método de atendimento e definição de estilo pessoal, eles necessitam da orientação e do acompanhamento afetivo que possam guiar seus primeiros passos. Após avançar na prática de atendimento individual, cada estagiário pode ainda ser treinado na condução de grupos terapêuticos e ser iniciado no atendimento de casais (Tavora, 2001).

Ao se deparar com o cliente à sua frente, o estagiário inicialmente lança mão de recursos de que já dispõe e que estão mais próximos de sua experiência. Ele tem noção de que deve ouvir, 
perguntar e dar algumas informações. Sabe também que deve evitar oferecer soluções prontas às solicitações do cliente. A partir daí, terá que aprender respostas totalmente novas, que necessitam de treino, feedback avaliativo dos colegas e apoio do supervisor.

\section{O PROCESSO DE SUPERVISÃO: DESENVOLVIMENTO DA MATRIZ DE IDENTIDADE PROFISSIONAL}

O grupo de supervisão é constituído pela supervisora e oito estagiários, em média. Vivências, estudos de textos, exercícios, discussão e dramatização dos casos em atendimento são atividades desenvolvidas com o objetivo de avaliação e desenvolvimento do papel de terapeuta. O estagiário é levado a refletir sobre suas habilidades, limitações, auto-imagem, relações dentro do grupo e evolução do seu processo de crescimento pessoal. As vivências iniciais geralmente seguem a ordem descrita aqui. Ao longo do processo, a escolha das atividades passa a ser orientada pelo próprio movimento do grupo e evolução pessoal de cada participante.

\section{Etapas do processo}

As etapas descritas seguem uma ordem evolutiva previsível, embora aconteçam segundo o ritmo de cada grupo e se mostrem pontilhadas de avanços e retrocessos. As vivências apresentadas são representativas de cada uma destas fases. No entanto, a duração de cada fase é variável, ajustando-se à necessidade do grupo, e pode durar até várias sessões de supervisão.

A compreensão do processo de aprendizagem do estagiário de psicologia clínica, à luz de sua evolução ao longo das fases da matriz de identidade, tem como base a observação do movimento que se repete com cada estudante que inicia o estágio, revelando suas necessidades de acompanhamento nesta trajetória e sua prontidão para entrar no mundo profissional ao final do estágio. As vivências apresentadas neste trabalho são apenas exemplos de situações que, vividas no grupo de supervisão, podem facilitar o crescimento do estudante em três etapas principais: inicialmente quando ele precisa compreender a si mesmo no contexto do desempenho do papel profissional que está iniciando, em seguida quando observa e ensaia colocar-se no lugar de outros (seus clientes e seus colegas de aprendizagem em supervisão), e finalmente quando já é capaz de envolver-se profundamente na relação terapêutica, tornando possível a vivência do encontro. As fases descritas a seguir ilustram esta evolução:

\section{Indiferenciação}

Este é o momento anterior ao primeiro atendimento do estagiário. Pode ter início algum tempo antes do começo do estágio e termina quando o cliente está finalmente sentado à frente do novo terapeuta. Nesta fase, o estagiário tenta organizar seu conhecimento teórico e visualizar um modelo de terapeuta, muitas vezes representado por alguém que considera ser um "papa" da abordagem teórica com que se identifica. Sua mente encontra-se povoada de imagens sobre o processo de atendimento; fantasia e realidade se confundem e se superpõem para formar uma imagem imprecisa de si mesmo como terapeuta.

Dado que esta fase se inicia antes do primeiro contato com o grupo de supervisão, o estudante já chega ao estágio com um drama interno em andamento. Ele precisa, assim, compartilhar suas dúvidas, ansiedade, inquietações, e sentir que não está sozinho no desafio em que se vai lançar. Identificar-se com vivências semelhantes de seus colegas e poder contar com a acolhida do supervisor são condições decisivas para um bom início de sua experiência como terapeuta.

\section{Reconhecimento do Eu}

No momento em que começa a atender, o estagiário inicia a fase do "eu comigo". Sua atenção está muito concentrada em si: o que faz de certo ou errado durante a sessão, se fala ou se fica calado, como ele próprio está se sentindo na presença do cliente. Sua condição para ouvir e estar disponível para o cliente fica em parte comprometida por sua necessidade de ouvir e acalmar a si mesmo.

A utilização da técnica de auto-exploração na supervisão facilita o contato consigo de que o estagiário necessita neste momento e inicia a elaboração de seus sentimentos positivos e negativos em relação a si mesmo. A conscientização de como estes sentimentos interferem na relação com o cliente começa a se desenvolver a partir daí.

\section{Técnica da auto-exploraçãa ${ }^{1}$}

Os participantes do grupo andam pela sala enquanto entram em contato com os recursos pessoais de que dispõem para iniciar o estágio. Em seguida, cada estagiário escreve, em uma folha de papel, suas características físicas, emocionais e intelectuais. Deve ressaltar, dentre estes aspectos, aqueles que deseja mudar e aqueles com os quais está satisfeito. A partir deste passeio interior, os estagiários apontam as habilidades que, neste ponto, consideram necessário

\footnotetext{
1 Modificação da vivência sugerida por Márcio Miranda. (1993, p. 47)
} 
desenvolver como terapeutas. A avaliação pessoal de cada estudante é colocada em um envelope lacrado, para que seja comparada com uma análise posterior no final do estágio.

Em seguida, cada estagiário é convidado a construir, com almofadas e as outras pessoas do grupo, sua própria imagem e dizer como se sente diante dela.

\section{Reconhecimento do Tu}

A atenção do estagiário volta-se neste momento para uma pessoa significativa de sua própria vida, elaborando pessoal e profissionalmente o reconhecimento de um 'outro' que pode satisfazer suas necessidades. Este outro é ainda instrumental, isto é, tem apenas a função de proporcionar ao indivíduo o ponto de referência de que ele necessita. É a fase do "Eu e o Outro".

O supervisor tem, nesse momento, um papel fundamental na confirmação, estímulo e consideração da pessoa do novo terapeuta. Este último precisa ser validado e reconhecido com suas potencialidades e limitações para que possa gradativamente também acolher a si mesmo com suas habilidades e imperfeições. Em outras palavras, o supervisor é uma 'pessoa significativa' para cada participante e para o grupo como um todo.

Ao refletir sobre como o outro se posicionou em sua vida, de forma a ter uma influência decisiva em seu desenvolvimento, o estagiário começa também a desenhar os contornos da pessoa significativa que ele próprio pode vir a ser para o cliente. A construção coletiva deste novo personagem inicia a transição deste momento para uma fase de pré-inversão.

\section{Técnica: pessoa significativa do grupo ${ }^{2}$}

Os participantes do grupo são convidados a andar pela sala e pensar sobre uma pessoa que tenha sido significativa na vida de cada um e que tenha feito diferença em seu crescimento. Quais as suas características? O que fez com que ela se tornasse uma pessoa significativa? Em seguida, eles devem construir coletivamente uma imagem da pessoa significativa do grupo, utilizando almofadas e os próprios participantes. Cada um, por sua vez, deve experimentar sua posição dentro da imagem e observar a distância, o quadro produzido. A partir dessa construção, eles vão avaliar a condição de se tornarem pessoas significativas no processo de crescimento de seus clientes.

2 Adaptação da vivência sugerida por Marcio Miranda. (1993, p. 45)
A vivência de "tarefas de desenvolvimento" acontece neste momento, potencializando a energia do estagiário para focalizar e investir no desenvolvimento de seus aspectos pessoais atrofiados ou subdesenvolvidos, ao mesmo tempo em que se torna também capaz de identificar as dificuldades evolutivas do cliente.

\section{Técnica: tarefas de desenvolvimento}

Em um determinado momento do atendimento, o terapeuta iniciante vê-se confrontado com suas tarefas de desenvolvimento bem ou mal-sucedidas, espelhadas pelas dificuldades trazidas por seus clientes. (Buys, 1987) É importante que ele avalie em que ponto de seu próprio desenvolvimento está e do que precisa para ajudá-los em sua caminhada. Para facilitar esta introspeção, o supervisor expõe as seguintes tarjas com algumas tarefas de desenvolvimento.

- Diferenciar-se dos valores dos pais

- Reconhecer o outro como diferente

- Lidar com os limites do outro

- Tornar claros os seus próprios limites

- Assumir riscos

- Responsabilizar-se pelas conseqüências do que faz

- Responsabilizar-se pela própria mudança

À medida que cada tarja é mostrada, o estagiário escreve, em uma folha de papel, uma palavra ou frase que esteja relacionada ao tema proposto. Cada tarefa de desenvolvimento deve passar de mão em mão de forma a obter três palavras ou frases de cada participante, totalizando uma soma de vinte e um itens para todas as tarefas.

A partir das palavras ou frases que escreveu, o estagiário deve criar uma história a ser compartilhada com os colegas. Uma reflexão conjunta se dá então, com o objetivo de identificar em que medida cada estagiário consegue ajudar seus clientes nas tarefas mencionadas e avaliar a relação das dificuldades encontradas no atendimento com suas tarefas de desenvolvimento pessoais.

\section{Pré-inversão}

Nesta fase, o estudante começa a imaginar-se no lugar do outro significativo e a exercitar-se no seu papel. Carece ainda, no entanto, de uma habilidade mais refinada para ser sua própria pessoa, espontânea e em condição de se relacionar em profundidade com a vivência do cliente. A identificação com o supervisor e a imitação deste podem acontecer neste momento, pois ele é o modelo concreto de que dispõe à sua frente. 
A próxima vivência leva o estagiário a refletir sobre as impressões que causa nos outros e a posição em que se coloca na relação com o cliente. Construindo sua própria imagem com ajuda dos colegas de supervisão, ele passa a perceber os sinais afetivos que transmite em suas relações, fazendo uma síntese entre sua percepção pessoal e sua imagem social.

\section{Técnica: percepção de si $^{3}$}

Cada estagiário escolhe três pessoas de seu convívio, dentro e fora da família, e escreve sobre como acha que cada uma destas pessoas o vê e o sente. Em seguida, o grupo passa a caminhar pela sala e as pessoas devem procurar identificar as mensagens que enviam e recebem umas das outras. A partir desta sensibilização, cada participante fala sobre como acha que está sendo percebido pelos outros. Esta 'imagem social' é comentada, modificada ou complementada pelos colegas do grupo.

\section{Técnica: auto-revelação}

Este momento é reservado para o compartilhar de situações vivenciadas pelo estagiário quando seus próprios sentimentos foram fortemente ativados na relação com o cliente. Situações de sedução, críticas, manipulação, agressividade ou apatia provocadas pelo cliente são dramatizadas e discutidas enquanto cada terapeuta expressa suas vivências na relação terapêutica, ao mesmo tempo em que procura compreender e trabalhar a motivação que está na base da conduta do cliente.

À medida que os estagiários enfrentam dificuldades em seus atendimentos individuais, eles são estimulados a pedir ajuda aos outros participantes do grupo. Estes ficam atentos, não só à busca de uma solução através de sugestões ou treino de respostas, mas principalmente à vivência do novo terapeuta e à conscientização de seus recursos pessoais para encontrar um estilo pessoal de resolução.

\section{Inversão de papéis e o encontro}

Esta é a fase do "Eu com o Outro". O amadurecimento profissional está-se efetivando enquanto o estagiário se diferencia do supervisor e de seus colegas para encontrar sua própria identidade profissional. $\mathrm{O}$ outro, seja ele o cliente ou um participante do grupo de supervisão, não é mais um mero instrumento para satisfazer suas necessidades de adequação, mas alguém com quem o novo terapeuta é agora capaz de estabelecer uma relação de mutualidade.

3 Adaptação da vivência sugerida por Tereza Cristina Erthal. (1995, p. 53)

\section{Técnica: átomo social no grupo}

Cada estagiário constrói seu átomo social dentro do grupo de supervisão, dispondo as outras pessoas no espaço físico da sala, de acordo com a distância afetiva em que dele se encontram e expressando como se sente. Os outros participantes vão complementando e modificando o que foi feito anteriormente à medida que formam uma grande teia relacional. Este é geralmente um momento de muita mobilização afetiva, em que os vínculos entre os estagiários são trabalhados e fortificados. Os estagiários terminam por envolver também a supervisora na delimitação de seus espaços afetivos no grupo, trabalhando também a natureza deste vinculo diferenciado. Esta vivência favorece a sintonia e a aceitação da experiência do outro, tornando possível um verdadeiro encontro no contexto da supervisão.

\section{Técnica: habilidades como terapeuta}

Cada participante recebe um feedback de todos os outros sobre suas habilidades como terapeuta: suas características que são percebidas como facilitadoras do desempenho do papel profissional. Esta imagem é obtida ao longo do processo de supervisão por meio dos relatos de casos, dramatizações, discussões teóricas e condição para auto-avaliação e autocorreção na condução do atendimento.

Esta é também a ocasião em que muitas vezes os estagiários dão alguma espécie de feedback à supervisora, comentando sobre como a vêem, a relação que estabelecem com ela e em que medida se identificam com sua forma de atuar. Este momento final estimula a expansão do processo de crescimento profissional além dos limites da supervisão.

Com o suporte da experiência vivencial e relacional, o estagiário passa por um treino de respostas e de técnicas de ação. No modelo proposto, o aluno aprende, desde os primeiros momentos de treinamento, que a aprendizagem da técnica é indissociável do desenvolvimento da condição para vivenciar uma relação significativa com o cliente. Desta forma, o treino de respostas terapêuticas deve ser interpretado como a instrumentalização de uma situação vivencial mais ampla, onde o profissional promove também o seu crescimento na medida em que ajuda o cliente a superar suas dificuldades, como mostra o exemplo a seguir:

\section{O Processo de ajuda no grupo}

Os estagiários estão compartilhando as ansiedades e dúvidas vivenciadas em seus atendimentos:

- Estagiário B: "Tive que telefonar para a casa do cliente porque precisava cancelar uma sessão. O 
problema é que ele não quer que ninguém de sua casa saiba que ele está em terapia. Ainda bem que ele mesmo atendeu o telefone... mas pareceu desconcertado..."

- Estagiária C: "Quando preciso ligar para um cliente, eu tenho muito cuidado em deixar recado sem dizer que sou alguém da clínica..."

- Estagiário B: "Eu tenho vontade é de dar uma 'lição pedagógica', explicar para ele que tem que ser assim: tenho que ligar mesmo!"

- Estagiário E: "Acho que esta forma fica muito agressiva..."

- Estagiário B: "O medo que tenho é que ele acabe me manipulando... que me faça entrar no seu joguinho..."

- Supervisora: "O que me chama a atenção, Pedro, é que você está prevendo que o cliente irá manipulálo no futuro. De que recursos você acha que dispõe para colocar seus limites como terapeuta e como pessoa na relação com o cliente?"

O estagiário B levanta-se e, pela primeira vez, diz que gostaria de dramatizar a sessão de atendimento que irá acontecer no dia posterior à supervisão. Nas supervisões anteriores, havia, por várias vezes, manifestado sua dificuldade e pouca disponibilidade para participar de dramatizações.

$\mathrm{O}$ estagiário $\mathrm{F}$ é escolhido para desempenhar o papel de cliente e o estagiário B se coloca na posição de terapeuta:

- Estagiário B (no papel de terapeuta): "Precisamos falar sobre um assunto: precisei telefonar para a sua casa. Você disse que não gostaria que eu ligasse, mas foi necessário desta vez. E, aí, como é que fica?"

Os atores invertem papéis para que o estagiário B responda à sua própria pergunta:

- Estagiário F (no papel de terapeuta, repete a última parte da fala do estagiário B): "Você disse que não gostaria que eu ligasse, mas foi necessário desta vez. E aí, como é que fica?"

- Estagiário B (no papel de cliente): "É. Eu lhe disse que não queria que você ligasse para a minha casa."

A supervisora solicita que os outros estagiários se coloquem no lugar do terapeuta para fazer sua própria abordagem do problema. Em seguida, a supervisora assume o papel de terapeuta:

- Supervisora (no papel de terapeuta): "José, eu estou preocupado com o telefonema que precisei dar para você. Não sei como você o recebeu, como se sentiu."
- Estagiário B (no papel de cliente): "Eu não gostei. As pessoas da minha casa ficaram me perguntando e eu tive que inventar desculpas."

- Supervisora (no papel de terapeuta): "Você se sentiu invadido, inseguro quanto ao que eu iria fazer."

- Estagiário B (no papel de cliente, confirma o que foi dito com um movimento de cabeça).

- Supervisora (no papel de terapeuta): "Estou sentindo necessidade de combinar com você uma forma de nos comunicarmos, no caso de uma necessidade, que não deixe você constrangido."

- Estagiário B (no papel de cliente): "Você pode ligar, até deixar recado, mas não diga que é meu terapeuta."

- Supervisora (no papel de terapeuta): "Parece que o que mais o perturbou foi não saber como eu ia me conduzir, ou se poderia realmente confiar que eu não o iria expor."

- Estagiário B (no papel de cliente; movimenta afirmativamente a cabeça e mantém a cabeça baixa).

Finalizada a dramatização, a supervisora pede para o estagiário B permanecer no lugar do cliente.

- Supervisora: "Como você está se sentindo no lugar do cliente, Pedro?"

- Estagiário B: (suspira) "Estou aliviado. Deu para 'clarear' as minhas dúvidas."

A supervisora insiste em indagar novamente sobre os seus sentimentos do momento:

- Estagiário B: "Quando eu entrei na Universidade, procurei sempre seguir uma conduta ética. No estágio, vi que precisava agir assim também com o cliente..."

A supervisora pede ao estagiário B para ficar no lugar do terapeuta e falar dos seus sentimentos, em vez de dar explicações sobre a sua conduta:

- Supervisora: "Como você está-se sentindo agora, no lugar do terapeuta?"

- Estagiário B: "Sinto-me mais em condições de falar com o cliente, lidar com a próxima sessão..."

- Supervisora: "Como se você agora pudesse cuidar também de si mesmo, levar em conta sua necessidade e não apenas a do cliente."

- Supervisora (voltando-se para o grupo como um todo): "Vejam a diferença: enquanto o Pedro buscava uma solução, a forma certa de agir como terapeuta, falou de forma um tanto irritada com e sobre o cliente. Ao entrar cm contato com sua necessidade e expressála, passou a se sentir diferente e mais disponível para entender também os sentimentos do cliente." 
- Estagiário E: "Eu achei que o Pedro estava precisando de apoio..."

A supervisora solicita que o estagiário E venha para o lugar de "ajudador" (o lugar que anteriormente era do terapeuta) e ajude o estagiário $\mathrm{B} \mathrm{cm}$ suas vivências no desempenho do papel de terapeuta.

- Estagiário E (no papel de 'ajudador'): "O que você precisa, sente necessidade nesta situação é..."

O diálogo prossegue por alguns minutos, ajudando o estagiário $\mathrm{B}$ a se colocar verdadeiramente no lugar de um cliente, agora falando de suas angústias, inseguranças e necessidade de acertar sempre em suas intervenções como terapeuta.

\section{A FINALIZAÇÃo DO ESTÁGIO}

Nos momentos finais do estágio, os estudantes elaboram suas metas de aplicação do que foi aprendido e um plano de ação para as pôr em prática. Fazem também uma estimativa das dificuldades que provavelmente irão enfrentar. Neste ponto, espera-se que cada novo profissional esteja pronto para fazer uma avaliação realista do que conseguiu realizar, do seu potencial a desenvolver e do caminho que ainda precisa percorrer. Os envelopes que foram lacrados no início do processo de supervisão são abertos e cada estagiário, comparando suas vivências nos diferentes momentos, pode então avaliar o seu próprio movimento de crescimento.

Após o treino básico, chega o momento do psicólogo clínico entrar no mercado de trabalho. Ele deve agora montar seu consultório e formar uma clientela. Necessita, neste ponto, principalmente de confiança para lidar com as angústias e incertezas de sua iniciação como profissional. Muitos procuram, por este motivo, estender mais um pouco sua condição de estudante, prolongando a permanência na clínicaescola para completar horas de atendimento, assistir alguns clientes que "ainda não podem ser deixados" ou simplesmente para participar informalmente dos encontros de supervisão.

Quando o estágio se aproxima do seu final, o supervisor começa a gradativamente perder a sua função. O profissional que está nascendo deve agora arriscar-se a dar os primeiros passos por si mesmo. Concluída a construção da base de sua identidade profissional, e fora dos muros protetores da universidade, ele terá que escolher e buscar o suporte de que ainda necessita nesta nova etapa que se inicia. $\mathrm{O}$ supervisor precisará também lidar com o desligamento de seus orientandos, com a transformação do vínculo pedagógico em uma relação profissional entre colegas e o início de uma nova caminhada com outros estagiários que estão chegando. O supervisor de um determinado grupo nunca é exatamente o mesmo do ano anterior: o seu papel de supervisor sempre é aprimorado ao longo de uma rica aprendizagem compartilhada por todos os envolvidos.

O cliente, por sua vez, chega ao final do caminho percorrido com seu terapeuta. É o momento de avaliação das dificuldades enfrentadas e dos desafios que ainda tem pela frente. Encontra-se diante de duas possibilidades de escolha: prosseguir sozinho levando consigo os reflexos de seu crescimento na terapia ou iniciar um novo processo com outro terapeuta. Qualquer das decisões certamente lhe parece arriscada nesse momento, exigindo dele investimento em novos vínculos, a exposição a outras formas de relação e o engajamento no desafio de cativar e ser cativado. O momento do desligamento é, sem dúvida, difícil e enriquecedor para todos os envolvidos. Supervisor, estagiário e cliente, estimulando o crescimento um do outro, precisam enfrentar e transpor os desafios desta passagem de vida concretizada pela finalização do estágio.

\section{REFERÊNCIAS BIBLIOGRÁFICAS}

Buys, R. S. (1987). Supervisão de psicoterapia: na abordagem humanista centrada na pessoa. São Paulo: Summus.

Costa, W. G. (1996). Socionomia_com expressão de vida: um modelo de sistematização da teoria de Moreno. Fortaleza: Fundação de Estudos e Pesquisas Socionômicas do Brasil.

Costa, W. G. (2000). Método psicodramático na supervisão do psicodrama terapêutica. Revista Brasileira de Psicodrama, 8 (1).

Erthal, T. C. (1995). Treinamento em psicoterapia vivencial. Petrópolis, RJ: Vozes.

Miranda, M. L. (1993). Construindo a relação de ajuda: guia do treinador. Belo Horizonte: Crescer.

Moreno, J. L. (1997). Psicodrama. São Paulo: Cultrix.

Rogers, C. R. (1978). Sobre o poder pessoal. (W.M.A. Pentedo, Trad.) São Paulo: Martins Fontes. (Trabalho original publicado em 1977)

Rogers, C. R. (1983). Um jeito de ser. (M.C.M. Kupfer, H. Lebrão $\&$ Y.S. Patto Trad.) São Paulo: EPU.

Tavora, M. T. (2001). Treinamento em psicoterapia individual, de grupo e de casal: um guia para supervisores e terapeutas iniciantes. Fortaleza: Programa Editorial Casa de José de Alencar.

Recebido em 07/11/2002

Revisado em 15/04/2002

Aceito em 26/04/2002 
